\title{
National Workshop/CME on Alternatives to Animal Experimentation in Medical Science Education
}

\author{
Syed Ziaur Rahman ${ }^{1}$, Umme Aiman ${ }^{1}$ and Mohammad A. Akbarsha ${ }^{2}$ \\ ${ }^{1}$ Department of Pharmacology, Jawaharlal Nehru Medical College, Aligarh Muslim University, Aligarh, India; \\ ${ }^{2}$ Mahatma Gandhi - Doerenkamp Center, Bharathidasan University, Tiruchirappalli, India
}

http://dx.doi.org/10.14573/altex.1405191

\section{Introduction}

The concept of alternatives to animal experimentation is relatively new to India (Akbarsha et al., 2013). The ethical issues regarding use of animals in life sciences and biomedical sciences gained attention with the work done by People for Animals (PfA), People for Ethical Treatment of Animals (PeTA) and Mahatma Gandhi-Doerenkamp Center (MGDC) established by Doerenkamp-Zbinden Foundation (Switzerland), and regulations and guidelines have been brought up by the regulatory authorities such as ICMR (Indian Council of Medical Research), CPCSEA (Committee for the Purpose of Control and Super-vision of Experiments on Animals), MCI (Medical Council of India), PCI (Pharmacy Council of India), MoEF (Ministry of Environment and Forests, Government of India) and UGC (University Grants Commission) during the past 10-15 years (Badyal et al., 2009; Shehnaz et al., 2012, 2011).

The Department of Pharmacology, Jawaharlal Nehru Medical College (JNMC), Aligarh Muslim University (AMU), Aligarh, has been active in this field since the early days of these developments (Rai and Singh, 2006). In 2006 the department started a separate laboratory known as Alternatives to Animal Experimentation Lab for training medical students in alternatives in pharmacology (Ranganatha and Kuppast, 2012) using software from various sources. Since then, the number of animals used for teaching and practice has been drastically reduced. The third issue of a dedicated manual on Alternatives to Animal Experiments by Dr Syed Z. Rahman and Dr Mohamed Tariq Salman was published this year.

With a view to further propagate the concept of alternatives among the scientific community of India utilizing the experience of the department, a national workshop-cum-CME (continuing medical education) on Alternatives to Animal Experimentation was organized at JNMC on February 24-25, 2014. The program was supported with grants from MCI and AMU. Fifty-two participants (postgraduates in the fields of pharmacology, physiology, anatomy, Unani medicine, etc.) received hands-on-training on the latest software available to replace the use of animals in teaching fundamental concepts of medical sciences, especially physiology and pharmacology. The lectures and training were provided by persons from different parts of India.

\section{Inauguration}

Prof. Shahjahan Bano (Dean, Faculty of Medicine, JNMC, AMU), in her introductory remarks, said that the workshop would help students to improve their skills in teaching and research by using simulators and software and without harming animals. Prof. Tariq Mansoor (Principal and Chief Medical Superintendent, JNMC) reminded listeners of their moral obligation to care for animals and to avoid causing pain and distress to them. Dr Chaitanya Koduri (Science Policy Advisor, PeTA India) lauded JNMC's efforts regarding non-animal methods in teaching and learning which fulfil the legal obligation to protect animals as prescribed in the Constitution of India. Dr Syed Z. Rahman (Organizing Secretary) said that the main objective of organizing the workshop was to provide participants with an opportunity to explore the expanding possibilities of alternatives to animal experimentation, to train and instill confidence in them for use of alternatives and to encourage them to adopt these alternatives in teaching and training. A souvenir-cum-scientific proceedings (edited by Dr Umme Aiman) was released on this occasion (Rahman, 2014).

\section{Keynote addresses}

In the first keynote address Prof. Krishan Chandra Singhal, a leading pharmacologist, summarized how animals played crucial roles in development of not only drugs but also surgical procedures. He, however, emphasized that these potential benefits could be attained without subjecting experimental animals to any form of suffering. While speaking about alternatives to animal experiments, he advocated that a committee of knowledgeable scientists and educationists should share a common platform for discussing the pros and cons of alternatives to animal experimentation, assessing input required for educational set-ups and finding funds for the purpose.

In the second keynote address Prof. Mohammad A. Akbarsha, Director and Chair, MGDC, explained that many animal experiments are not relevant to humans owing to species differences, particularly pertaining to phase I and phase II metabolic enzymes. He elaborated on the evolution of in vitro and in silico approaches in drug discovery and toxicology and introduced cell 
culture methods, Integrated discrete Multiple Organ Co-culture (IdMOC) technology, stem cell applications, tissue engineering, organ-on-chip, human-on-chip technologies and high-throughput approaches to screening of potential drug candidates and risk assessment as well as non-mammalian model organisms such as Caenorhabditis elegans, zebrafish, drosophila and hydra. He explained how these alternatives could be equivalent to, or even better than, animal models. He quoted a passage from the Holy Quran stating that animals are like human beings and so need to be respected and treated with kindness. He stressed the need to work along the current trend of available and upcoming technologies in order to keep pace with global developments.

\section{CME lectures}

In the first lecture titled Historical perspectives of alternatives to animal experiments, Prof. Mohamed Mobarak Hossein traced the history of alternative methods, starting from the landmark book The Principles of Humane Experimental Technique by Russell and Burch in 1959. He explained that alternative methods have matured from a perceived or fabricated threat to biomedical research to an obvious opportunity for advancement without causing pain and distress to animals. Then, Dr Mohamed T. Salman spoke on The Scope of Alternatives to Animal Experimentation in Pharmacology. He described the way in vitro cell and tissue culture methods have reduced the use of rodents in the initial screening of potential new drugs. He also focused on examples of human skin equivalent tests (like EpiDerm, EpiSkin, SkinEthic, etc.) being used as alternatives to animal-based corrosive and irritation studies and of corneas from slaughtered cows or chicken eyes used for eye irritation studies. The final lecture was delivered on The Conception of Animal Simulators from Idea to Product: A Challenging Jour$n e y$ by a spokesperson of Elsevier who presented the way alternatives software is conceptualized and developed.

\section{Hands-on training in alternatives software}

The participants were divided into four groups. Parallel onehour sessions were conducted at four different stations: The participants received hands-on training on simulators/software made in India, such as ExPharm, ExPhysio and ExCology, by the software originators, Prof. Ramaswamy Raveendran (Jawaharlal Institute of Postgraduate Medical Education and Research [JIPMER], Pondicherry), Prof. Sandhya T. Avadhany (St. John's Medical College, Bangalore), Prof. Mohammad A. Akbarsha (MGDC), Prof. S. K. Bajaj (Maulana Azad Medical College, New Delhi) and Prof. Chandragouda R. Patil (R. C. Patel College of Pharmacy, Dhule), in addition to other experts working in the same field.

\section{Valedictory function}

Prof. Mohammad A. Akbarsha, the Chief Guest, said he hoped that the workshop/CME had motivated the participants to employ alternatives to animal experimentation and stated that it is high time to adopt the available technologies, and also develop further technologies at affordable costs. Prof. Sandhya T. Avad- hany and Prof. Ramaswamy Raveendran, Guests of Honor, congratulated the organizers on the well-organized workshop and appreciated the opportunity to learn about the e-resources. Dr Syed Z. Rahman, Organizing Secretary, thanked all the contributors, participants, administration and funding agencies for supporting and making this workshop successful.

\section{Conclusion}

At the end of the workshop, feedback was collected from participants. Most of them rated the workshop/CME at point 4 on the Lickert scale. The workshop was successful in creating awareness and enhancing acceptability of alternatives. The participants were willing to use modern techniques in the form of alternatives, and this program provided them a good platform towards this end. Most of the participants urged to have similar workshops on a regular basis.

\section{References}

Akbarsha, M. A., Zeeshan, M. and Meenekumari, K. J. (2013). Alternatives to animals in education, research and risk assessment: An overview with special reference to Indian context. ALTEX Proc 2, 5-19. http://www.altex.ch/resources/ rISC_001_Akbarsha2.pdf

Badyal, D. K., Modgill, V. and Kaur, J. (2009). Computer simulation models are implementable as replacements for animal experiments. Altern Lab Anim 37, 191-195. http://www.frame. org.uk/atla_article.php?art_id=1161\&abstract=true

Rahman, S. Z. (2014). National Workshop cum CME on Alternatives to Animal Experimentation. Newsletter of Ibn Sina Academy 14, 10-11.

Rai, J. and Singh, A. (2006). A study of trend of animal experimentation in medical education in India. JK Science 8 , 92-94.

Ranganatha, N. and Kuppast, I. J. (2012). A review on alternatives to animal testing methods in drug development. International Journal of Pharmacy and Pharmaceutical Sciences 4, 28-32.

Shehnaz, S. I., Sreedharan, J., Mathew, E. et al. (2011). Willingness to spare animals in undergraduate medical education in Southern India: a preliminary questionnaire-based investigation. Altern Lab Anim 39, 557-566. www.frame.org.uk/atla_ article.php?art_id=1394\&abstract=true

Shehnaz, S. I., Sreedharan, J., Arifulla, M. et al. (2012). Do faculty in Southern Indian medical colleges support animal use in postgraduate education more than in undergraduate education? Altern Lab Anim 40, 165-174. http://www.frame.org.uk/atla_ article.php?art_id=1427\&abstract=true 